\title{
First-Line Drug Resistance Patterns of Mycobacterium tuberculosis Complex Isolates from Re-Treatment Patients from Sudan
}

\author{
Muatsim Ahmed Mohammed Adam¹, Hamdan Mustafa Hamdan Ali², Eltahir Awad Gasim Khalil ${ }^{3 *}$ \\ ${ }^{1}$ National Tuberculosis Reference Laboratory, National Public Health Laboratory, Federal Ministry of Health, Khartoum, Sudan \\ ${ }^{2}$ National Tuberculosis Control Program, Federal Ministry of Health, Khartoum, Sudan \\ ${ }^{3}$ Tuberculosis Research Group/Institute of Endemic Diseases, University of Khartoum, Khartoum, Sudan \\ Email:muatsimadam@hotmail.com,drhamdanmh@gmail.com, ‘eltahirk@iend.org
}

How to cite this paper: Adam, M.A.M., Ali, H.M.H. and Khalil, E.A.G. (2016) First-Line Drug Resistance Patterns of Mycobacterium tuberculosis Complex Isolates from ReTreatment Patients from Sudan. Journal or Tuberculosis Research, 4, 98-104. http://dx.doi.org/10.4236/jtr.2016.43012

Received: June 16, 2016

Accepted: August 15, 2016

Published: August 18, 2016

Copyright $\odot 2016$ by authors and Scientific Research Publishing Inc. This work is licensed under the Creative Commons Attribution International License (CC BY 4.0)

http://creativecommons.org/licenses/by/4.0/ (c) (i) Open Access

\begin{abstract}
Drug susceptibility testing (DST) plays a pivotal role in TB patients' management leading to the selection of most effective drugs. This study aimed to determine resistance patterns to first line anti-TB drugs in Mycobacterium tuberculosis isolates from re-treated patients from Sudan. A total of 239 sputum specimens were collected from smear positive re-treatment TB patients during the period from July 2009 to July 2010. Specimens were pre-treated according to Petroff method. The recovered isolates were tested for sensitivity to first line anti-TB drugs by the $1 \%$ proportion method. One hundred and forty three $(143 / 239,59.8 \%)$ mycobacterial isolates were successfully recovered. The majority $(98.6 \%, 141 / 143)$ of the isolates were Mycobacterium tuberculosis complex strains. Two strains $(2 / 143,1.4 \%)$ were identified as RIF/INH-resistant MOTT, while fifty four isolates (38.3\%, 54/141) were MDR. Multidrug resistant Mycobacterium tuberculosis complex (MDR-TB) among re-treatment patients from national referral centers for tuberculosis diagnosis and management was considerably high in the study isolates.
\end{abstract}

\section{Keywords}

MDR, Sudan, TB, Re-Treatment, DST

\section{Introduction}

Exposure to anti-tuberculosis drugs is an important risk factor for developing drug resistant TB [1]. Drug resistance is a growing burden; it has increased since the first drug treatment for TB was introduced in 1943 [2]. Recent years have witnessed worldwide 
emergence of multi-drug resistant TB (MDR-TB). MDR-TB is defined as resistance to at least rifampicin and isoniazid [3]. The prevalence of MDR-TB in retreatment cases is ( $30 \%$ to $80 \%$ ), countrywide [4]. When first line drugs fail, second line drugs are used to treat MDR-TB, they are less effective, more toxic and expensive. Improper use of these drugs has fuelled the generation and subsequent emergence of highly resistant strains of TB termed extensively drug resistant tuberculosis, or (XDR-TB). XDR-TB is defined as MDR-TB with additional resistance to any fluoroquinolone and to at least one of three injectable drugs used for TB treatment: capreomycin, kanamycin, or amikacin [5] [6].

Sudan carries $8 \%$ of the estimated TB burden in the Eastern Mediterranean Region, EMRO. In 2011, the estimated incidence of TB cases was 117 per 100,000 individuals (95\% CI: 98 - 142), translating to 39,760 TB cases annually [7]. But, the true magnitude is not clear. In 2012 National Tuberculosis Control Program (NTP) of Sudan reported $19 \%$ MDR in re-treatment cases and $1.8 \%$ in new cases. MDR-TB in Sudan was 5\% in new cases and $24 \%$ in previously treated patients as reported by Sharaf Eldin and colleagues in 2011 [8]. While another study from Northeastern part of Sudan reported 6\% MDR in new cases [9].

\section{Materials and Methods}

\subsection{Study Specimens' Origin}

Smear positive sputum specimens were collected during the period from July 2009 to July 2010. Specimens were collected from national referral centers for Tuberculosis diagnosis and management in Abu Anja Specialized TB Hospital, Academic Hospital and the National Public Health Laboratory; Greater Khartoum, Sudan.

\subsection{Study Subjects}

Sputa included were from smear positive retreatment TB cases, treatment failures, return after default and relapsed patients based on their willingness to participate in the study. New cases of TB and smear negative retreatment TB cases were excluded.

\subsection{Study Design}

This is a prospective, cross-sectional and hospital-based study.

\subsection{Isolation of Mycobacteria}

Lowenstein-Jensen medium (L. J.) containing glycerol and Lowenstein-Jensen supplemented with pyruvate were used for isolation of mycobacteria from sputum specimens. Petroff method for decontamination ( $4 \% \mathrm{NaOH}$ for 20 minutes) was used to homogenize and decontaminate specimens. All cultures were incubated in slope position for three days with loosen caps to evaporate the excess fluid then caps were closed tightly to prevent drying of media, placed on upright position. Re-examination was taken at first week to detect rapid growers and every week to detect slow growers up to eight weeks. The result was recorded as negative if no growth appeared, and recorded as positive when it gives growth. 


\subsection{Identification of Mycobacteria}

Isolates were firstly identified according to their reaction with $\mathrm{ZN}$ staining method, growth rate, colonial morphology and pigment production and by their susceptibility to Para nitro benzoic acid (PNB).

\subsection{Data Collection Methods}

A questionnaire was designed for patient's data and a register for laboratory data. The questionnaire included information about: sex, age, history of treatment, and visual appearance of sputum.

\subsection{Drug Susceptibility Test (DST)}

DST was performed following the standard proportion method. First line Anti-TB drugs were added to reach different critical concentrations as follows: Rifampicin (RIF), $40.0 \mu \mathrm{g} / \mathrm{ml}$; Isoniazid (INH), $0.2 \mu \mathrm{g} / \mathrm{ml}$; Ethambutol (ETH), $2.0 \mu \mathrm{g} / \mathrm{ml}$ and Streptomycin (STM), $4.0 \mu \mathrm{g} / \mathrm{ml}$ [10]; an amount of $0.1 \mathrm{ml}$ of $10^{-4}$ bacillary suspension were inoculated onto two slopes of L. J (drug free) medium as control 2, same amount of $10^{-2}$ bacillary suspension was also inoculated onto two slopes of L. J (drug free) media as control 1; and two slopes of L. J (drug containing) media were inoculated. Cultures were examined after six weeks and considered sensitive if the percentages of colonies on drug containing media were less than $1 \%$ compared with control 2 and considered resistant if the proportion of growth was equal or greater than $1 \%$.

\section{Results}

\subsection{Demographic Data}

Two out of the enrolled cases $(0.8 \%, 2 / 239)$ were from patients under 15 years of age, while the rest $(99.2 \%, 237 / 239)$ were $>15$ years of age. Return after Default were $50.6 \%$ (121/239); relapsed were $26.4 \%$ (63/239), while the treatment failures were $23 \%$ (55/239). Relapsed cases were of an age that is significantly higher that of the return after default and the treatment failures $(p<0.001)$, while return after default and treatment failures have similar mean ages $(p=0.7)$. The overall male female ratio was $3: 1$, but the balance is completely tipped towards males in the return after default group where ratio was 5:1.

\subsection{Sputa Collection Sites Isolates Types and Growth Behavior}

The majority of specimens came from the National Public Health Laboratory (45.2\%, 108/239). Comparable numbers came from Abu Anja (29.3\%, 70/239) and The Academic Hospitals $(25.5 \%, 61 / 239)$. More than half $(59.8 \%, 143 / 239)$ of the isolates were successfully recovered, while $40.2 \%$ (96/239) failed to grow. The majority of the isolates (98.6\%, 141/239) were identified as Mycobacterium tuberculosis complex, while a small percentage $(1.4 \%, 2 / 143)$ were identified as Mycobacteria Other Than Tuberculosis (MOTT). 


\subsection{Drug Resistance Patterns (Table 1 and Table 2)}

The frequency of MDR was equal to pan-susceptible isolates at $38.3 \%$ (54/141). Mono and poly-resistance trails were $17 \%(24 / 141)$ and $6.4 \%$ (9/141) respectively. IsoniazidStreptomycin combination was the most prevalent poly-resistant pattern with a frequency of $4.3 \%(6 / 141)$. Streptomycin was the most prevalent mono-resistant drug with a frequency of $12 \%$ (17/141). Both MOTT isolates were shown to be pan-resistant. MDR-TB

Table 1. Patterns of resistance to first line anti-TB drugs.

\begin{tabular}{ccc}
\hline Drug resistance pattern & No of patients & Frequency $\%+$ \\
\hline Pan-susceptible & 54 & 38.3 \\
MDR & 54 & 38.3 \\
RHSE & 18 & 12.8 \\
RHS & 14 & 9.9 \\
RHE & 14 & 9.9 \\
RH & 8 & 5.8 \\
Poly resistance & 9 & 6.4 \\
RSE & 1 & 7 \\
HSE & 2 & 1.4 \\
HS & 6 & 4.2 \\
Mono resistance & 24 & 17 \\
R & 2 & 1.4 \\
H & 3 & 2.1 \\
S & 17 & 12 \\
E & 2 & 1.4 \\
Total & 141 & $100 \%$ \\
\hline
\end{tabular}

$\mathrm{R}=$ Rifampicin; $\mathrm{H}$ = Isoniazid; $\mathrm{S}=$ Streptomycin; $\mathrm{E}=$ Ethambutol.

Table 2. Patterns of resistance to first line anti-TB drugs in different patients' categories.

\begin{tabular}{|c|c|c|c|c|c|}
\hline \multirow{2}{*}{$\begin{array}{l}\text { Patients' } \\
\text { Categories }\end{array}$} & \multicolumn{5}{|c|}{ Resistance pattern } \\
\hline & MDR & Poly resistance & $\begin{array}{c}\text { Mono } \\
\text { resistance }\end{array}$ & Pan-susceptible & Total \\
\hline \multicolumn{6}{|l|}{ Treatment } \\
\hline Failures & 27 & 3 & 2 & 4 & 36 \\
\hline $\begin{array}{c}\text { Return after } \\
\text { Default }\end{array}$ & 15 & 4 & 15 & 37 & 71 \\
\hline Relapsed & 12 & 2 & 7 & 13 & 34 \\
\hline Total & 54 & 9 & 24 & 54 & 141 \\
\hline
\end{tabular}


isolates were significantly more abundant among patients who failed treatment (75\%, 27/36) compared to pan-susceptible and mono/poly-resistant isolates. Most returnees after default (37/71, 52.1\%) were pan-susceptible.

\section{Discussion}

Age groups and genders affected by TB did not change over time as is shown by our findings [11] [12]. MDR is more in males compared to female. The highest proportion of patients was in the 25 - 44-year in agreement with previous reports [12] [13]. It is not surprising that the culture recovery rate was low in this study; this may be due to the fact that patients were treated before with a rifampicin-containing regimen where sputa become culture-negative by the third week of treatment. In addition, loss of viability or death of micro-organisms after storage for long periods of time in fridge and subsequent subculture probably resulted from heat and/or cold shock this has been reported previously [14]-[16].

MOTT was reported at a low rate in specimens as expected, this bacteria originates from the soil and water and infects patients with chronic pulmonary disease (e.g. cystic fibrosis) or immune-compromized patients (e.g. chronic granulomatous disease). HIV sero-status for patients with MOTT infection was not known, one of them is a farmer and the other is a merchant in a dusty market [17]-[19].

MDR-TB is a man made phenomenon with previous history of receiving treatment as a main factor [1] [2]. As expected our findings showed that MDR is at its highest in treatment failures followed by relapses and return after default. But, this may reflect referral or the selection bias of hospital-based studies similar to results from other countries in the region [20] [21]. In addition the isolates were collected at time when second line treatment was not started and MDR patients accumulated.

The wide and the long term use of streptomycin (SM) and isoniazid (INH) (since 1947/1952) was clearly reflected on the high proportion of mono and poly-resistance seen in our cohort in agreement with previous reports [15] [21]-[24]. Streptomycin use was stopped few months ago by the Sudan National TB Control Program. The low levels of Rifampicin (RIF) mono-resistance among our cohort clearly indicates that RIF mono-resistance is rare, as well as resistance to INH. Hence, a positive result for RIF's resistance could be a useful surrogate marker of MDR-TB as reported previously [19] [25] [26].

\section{Conclusion}

In conclusion, Multi-drug resistant Mycobacterium tuberculosis complex (MDR-TB) among re-treatment patients from national referral centers for tuberculosis diagnosis and management was considerably high in the study isolates.

\section{References}

[1] Sharma, S.K., Kumar, S., Saha, P.K., George, N., Arora, S.K., Gupta, D., Singh, U., Hanif, M. and Vashisht, R.P. (2011) Prevalence of Multidrug-Resistant Tuberculosis among Category 
II Pulmonary Tuberculosis Patients. Indian Journal of Medical Research, 133, 312-315.

[2] World Health Organization (2008) Guidelines for the Programmatic Management of DrugResistant Tuberculosis Emergency update 2008. (WHO/HTM/TB/2008.402)

[3] Nathanson, E., Weezenbeek, C.L., Rich, M.L., Gupta, R., Bayona, J., Blöndal, K., Caminero, J.A., Cegielski, J.P., Danilovits, M., Espinal, M.A., Hollo, V., Jaramillo, E., Leimane, V., Mitnick, C.D., Mukherjee, J.S., Nunn, P., Pasechnikov, A., Tupasi, T., Wells, C. and Raviglione, M.C. (2006) Multidrug-Resistant Tuberculosis Management in Resource-Limited Settings. Emerging Infectious Diseases, 12, 1389-1397 www.cdc.gov/eid http://dx.doi.org/10.3201/eid1209.051618

[4] Ormerod, L.P. (2005) Multidrug-Resistant Tuberculosis (MDR-TB): Epidemiology, Prevention and Treatment. British Medical Bulletin, 73-74, 17-24.

[5] Burgos, M., Gonzalez, L.C., Paz, E.A., Gournis, E., Kawamura, L.M., Schecter, G., Hopewell, P.C. and Daley, C.L. (2005) Treatment of Multidrug-Resistant Tuberculosis in San Francisco: An Outpatient-Based Approach. Clinical Infectious Diseases, 40, 968-975. http://dx.doi.org/10.1086/428582

[6] Jacobson, K.R., Tierney, D.B., Jeon, C.Y., Mitnick, C.D. and Murray, M.B. (2010) Treatment Outcomes among Patients with Extensively Drug-Resistant Tuberculosis: Systematic Review and Meta-Analysis. Clinical Infectious Diseases, 51, 6-14. http://dx.doi.org/10.1086/653115

[7] Sudan National Tuberculosis Control Programme. Progress Report January-December. Federal Ministry of Health. General Directorate of Primary Health Care, 2012.

[8] Sharaf Eldin, G.S., Fadl-Elmula, I., Ali, M.S., Ali, A.B., Salih, A.G.A., Mallard, K., Bottomley, C. and McNerney, R. (2011) Tuberculosis in Sudan: A Study of Mycobacterium tuberculosis Strain Genotype and Susceptibility to Anti-Tuberculosis Drugs. BMC Infectious Diseases, 11, 219. http://dx.doi.org/10.1186/1471-2334-11-219

[9] Hassan, S.O., Musa, M.T., Elsheikh, H.M., Eleragi, A.M.S. and Saeed, N.S. (2012) Drug Resistance in Mycobacterium tuberculosis Isolates from Northeastern Sudan. British Journal of Medicine \& Medical Research, 2, 424-433. http://dx.doi.org/10.9734/BJMMR/2012/1404

[10] World Health Organization. Policy Guidance on Drug-Susceptibility Testing (DST) of Second-Line Anti Tuberculosis Drugs. Geneva WHO/HTM/TB/2008b.392.

[11] World Health Organization. Assessing Tuberculosis Prevalence through Population-Based Surveys. 2007aISBN 9789290613145 (NLM Classification: WF 300).

[12] Saeed, W., Naseem, A. and Ahmed, J. (2009) Retrospective Audit of Patients Treated for MDR-TB in Retreatment Category. Journal Pakistan Medical Association, 21, S70-S74.

[13] Dalton, T., Cegielski, P., Akksilp, S., Asencios, L., Caoili, J.C., Cho, S., Erokhin, V.V., Ershova, J., Gler, M.T., Kazennyy, B.Y., Kim, H.J., Kliiman, K., Kurbatova, E., Kvasnovsky, C., Leimane, V., van der Walt, M., Via, L.E., Volchenkov, G.V., Yagui, M.A. and Kang, H., the Global PETTS Investigators (2012) Prevalence of and Risk Factors for Resistance to SecondLine Drugs in People with Multidrug-Resistant Tuberculosis in Eight Countries: A Prospective Cohort Study. The Lancet, 380, 1406-1417. www.thelancet.com

[14] Frieden, T. (2004) Toman's Tuberculosis Case Detection, Treatment, and MonitoringQuestions and Answers. WHO/HTM/TB, 334, 2nd Edition. (NLM Classification: WF 360)

[15] Mdivani, N., Zangaladze, E., Volkova, N., Kourbatova, E., Jibuti, T., Shubladze, N., Kutateladze, T., Khechinashvili, G., del Rio, C., Salakaia, A. and Blumberg, H.M. (2008) High Prevalence of Multidrug-Resistant Tuberculosis in Georgia. International Journal of Infectious Diseases, 12, 635-644. http://intl.elsevierhealth.com/journals/ijid http://dx.doi.org/10.1016/j.ijid.2008.03.012 
[16] Umubyeyi, A., Rigouts, L., Shamputa, I.C., Dediste, A., Struelens, M. and Portaels, F. (2008) Low Levels of Second-Line Drug Resistance among Multidrug-Resistant Mycobacterium tuberculosis Isolates from Rwanda. International Journal of Infectious Diseases, 12, 152-156. http://intl.elsevierhealth.com/journals/ijid http://dx.doi.org/10.1016/j.ijid.2007.05.003

[17] Magdorf, K., Ertel, M., Grassot, A. and Wahn, U. (1996) Tuberculin Conversion and Abnormal Chest Radiograph in an Infant. European Respiratory Journal, 9, 1763-1765. http://dx.doi.org/10.1183/09031936.96.09081763

[18] Girón, R.M., Domingo, D., Buendía, B., Antón, E., Ruiz-Velasco, L.M. and Ancochea, J. (2005) Nontuberculous mycobacteria in Patients with Cystic Fibrosis. Archivos de Bronconeumología, 41, 560-565.

[19] Nasiri, M.J., Rezaei, F., Zamani, S., Darban-Sarokhalil, D., Fooladi, A.A.I., Shojaei, H. and Feizabadi, M.M. (2014) Drug Resistance Pattern of Mycobacterium tuberculosis Isolates from Patients of Five Provinces of Iran Asian Pacific. Journal of Tropical Medicine, 193-196. www.elsevier.com/locate/apjtm

[20] Shamaei, M., Marjani, M., Chitsaz, E., Kazempour, M., Esmaeili, M., Farnia, P., Tabarsi, P., Amiri, M.V., Mirsaeidi, M., Mansouri, D., Masjedi, M.R. and Velayati, A.A. (2009) FirstLine Anti-Tuberculosis Drug Resistance Patterns and Trends at the National TB Referral Center in Iran-Eight Years of Surveillance. International Journal of Infectious Diseases, 13, e236-e240. http://intl.elsevierhealth.com/journals/ijid http://dx.doi.org/10.1016/j.ijid.2008.11.027

[21] Abate, D., Taye, B., Abseno, M. and Biadgilign, S. (2012) Epidemiology of Anti-Tuberculosis Drug Resistance Patterns and Trends in Tuberculosis Referral Hospital in Addis Ababa, Ethiopia. BMC Research Notes, 5, 462. http://www.biomedcentral.com/1756-0500/5/462 http://dx.doi.org/10.1186/1756-0500-5-462

[22] Cegielski, J.P. (2010) Extensively Drug-Resistant Tuberculosis: “There Must Be Some Kind of Way Out of Here". Clinical Infectious Diseases, 50, S195-S200. http://dx.doi.org/10.1086/651491

[23] Daniel, O., Osman, E., Oladimeji, O. and Dairo, O.O. (2013) Pre-Extensive Drug Resistant Tuberculosis (Pre-XDR-TB) among MDR-TB Patients in Nigeria. Global Advanced Research Journal of Microbiology, 2, 22-25. http://garj.org/garjm/index.htm

[24] Ndung'u, P.W., Kariuki, S., Ng'ang'a, Z. and Revathi, G. (2012) Resistance Patterns of $M y$ cobacterium tuberculosis Isolates from Pulmonary Tuberculosis Patients in Nairobi. Journal of Infection in Developing Countries, 6, 33-39.

[25] Mani, C., Selvakumar, N., Narayanan, S. and Narayanan, P.R. (2001) Mutations in the rpoBGene of Multidrug-Resistant Mycobacterium tuberculosis Clinical Isolates from India. Journal of Clinical Microbiology, 39, 2987-2990. http://dx.doi.org/10.1128/JCM.39.8.2987-2990.2001

[26] Yam, W.C., Tam, C.M., Leung, C.C., Tong, H.L., Chan, K.H., Leung, E.T.Y., Wong, K.C., Yew, W.W., Seto, W.H., Yuen, K.Y. and Ho, P.L. (2004) Direct Detection of RifampinResistant Mycobacterium tuberculosis in Respiratory Specimens by PCR-DNA Sequencing Journal of Clinical Microbiology, 42, 4438-4443. http://dx.doi.org/10.1128/JCM.42.10.4438-4443.2004 
Submit or recommend next manuscript to SCIRP and we will provide best service for you:

Accepting pre-submission inquiries through Email, Facebook, LinkedIn, Twitter, etc. A wide selection of journals (inclusive of 9 subjects, more than 200 journals)

Providing 24-hour high-quality service

User-friendly online submission system

Fair and swift peer-review system

Efficient typesetting and proofreading procedure

Display of the result of downloads and visits, as well as the number of cited articles

Maximum dissemination of your research work

Submit your manuscript at: http://papersubmission.scirp.org/ 